\title{
Percepção ambiental sobre a viabilidade da implantação de um sistema de reciclagem de óleo de cozinha no município de Caçador, Santa Catarina, Brasil
}

O óleo de cozinha usado traz inúmeros problemas para o meio ambiente e põe em risco nossa saúde se descartado incorretamente. Portanto, o presente trabalho tem como objetivo analisar a percepção ambiental dos moradores do município de Caçador/SC quanto ao processo de gestão dos resíduos de óleo de cozinha nas residências, com a perspectiva da implantação de um programa de reciclagem do óleo de cozinha em biodiesel. O estudo apresenta a viabilidade da implantação de um programa de transformação do resíduo óleo de cozinha em biodiesel, porém para uma maior eficiência do sistema é necessário o auxílio de entidades públicas e privadas através da aplicação de educação ambiental para a comunidade.

Palavras-chave: Óleo de Cozinha; Percepção Ambiental; Educação Ambiental.

\section{Environmental perception on the feasibility of the implantation of a kitchen oil recycling system in the municipality of Caçador, Santa Catarina, Brazil}

\footnotetext{
Used cooking oil brings numerous problems to the environment and puts our health at risk if discarded incorrectly. Therefore, the present work has the objective of analyzing the environmental perception of the residents of the city of Caçador/SC regarding the process of management of cooking oil residues in the residences, with the perspective of the implementation of a program of recycling cooking oil into biodiesel. The study presents the feasibility of implementing a program to transform the cooking oil residue into biodiesel, but for a greater efficiency of the system it is necessary the assistance of public and private entities through the application of environmental education to the community.

Keywords: Kitchen Oil; Environmental Perception; Environmental Education.
}

Topic: Educação Ambiental

Reviewed anonymously in the process of blind peer.
Received: 11/03/2017

Approved: 12/05/2017
Roger Francisco Ferreira de Campos

Universidade do Estado de Santa Catarina, Brasil

http://lattes.cnpq.br/9523087825034013

rogerffcampos@gmail.com

\section{Tiago Borga}

Universidade Alto Vale do Rio do Peixe, Brasil

http://lattes.cnpq.br/6454805020822521

tiagoborga@gmail.com

Andrei Felipe Nunes de Lima

Universidade Alto Vale do Rio do Peixe, Brasil

http://lattes.cnpq.br/1747199653890715

andreifelipe12@hotmail.com
Referencing this:

CAMPOS, R. F. F.; BORGA, T.; LIMA, A. F. N.. Percepção ambiental sobre a viabilidade da implantação de um sistema de reciclagem de óleo de cozinha no município de Caçador, Santa Catarina, Brasil. Revista Ibero-Americana de Ciências Ambientais, v.8, n.3, p.228-237, 2017. DOI: http://doi.org/10.6008/SPC2179-6858.2017.003.0021 


\section{INTRODUÇÃO}

Entre as questões de impacto no meio ambiente, um dos principais impasses ambientais são os relacionados com os Resíduos Sólidos, sendo um sério desafio para a atualidade. 0 crescimento populacional e o aumento do grau de desenvolvimento urbano não estão sendo associado junto com as medidas necessárias para dar um destino adequado ao Resíduo Sólido produzido (BRAGA et al., 2005). Dentre os resíduos sólidos, o óleo de cozinha é proveniente de residências, comércio e indústrias (GONÇALVES et al., 2014), e quando descartado de forma inadequada, apresenta sérios danos ao meio ambiente (MARTINS et al., 2010).

Segundo Godoy et al. (2010), o descarte de óleo de cozinha na rede coletora de esgoto por estabelecimento comerciais e residenciais é muito comum, ocasionando problemas de higiene, proliferação de mau cheiro, entupimento de tubulações e afetando o funcionamento das estações de tratamento de esgoto. Quando há a destinação correta do resíduo de óleo de cozinha por estabelecimentos comerciais, essa ação está associada ao processo de comercialização do produto e não por conscientização ou políticas ambientais (GOMES et al., 2013).

Para Castellanelli et al. (2007) o descarte inadequado do resíduo óleo de cozinha está associado a falta de conscientização e educação ambiental sobre o assunto. Segundo Hanisah et al. (2013), a educação ambiental nas escolas com ênfase nos problemas dos resíduos de óleo de cozinha é um meio para revolver a falta de conscientização sobre o assunto, visto que os alunos levam as informações recebidas em sala de aula para suas residências. Trevisol (2003) complementa que de uma forma geral à educação ambiental pode resolver os problemas entre o homem e a natureza.

Embora a geração do óleo de cozinha seja um problema na atualidade, existem diferentes técnicas para seu tratamento. Para Godoy et al. (2010), é simples a pratica das técnicas de reciclagem do óleo de cozinha com a comunidade, porém, para isso é necessário o apoio corretos dos envolvidos. Segundo Chhetri et al. (2008), a utilização do óleo de cozinha para a produção de biodiesel é um alternativa para substituir a demanda dos combustíveis fosseis e os problemas ambientais. A logística reversa também apresente ser uma alternativa para o cenário do óleo de cozinha no Brasil, porém para haver essa ação necessita do aprimoramento das legislações e incentivo do governo (GONÇALVES et al., 2014).

Para reverter a situação dos problemas ambientais na atualidade, é necessário preservar e minimizar os impactos ao meio ambiente; essa questão tem que partir de nós, seres humanos, pois possuímos a capacidade de buscar meios viáveis para melhor as condições socioambiental atual e reverter as consequências negativas geradas no decorrer de nossas vidas (MARTINS et al., 2010). Para diminuir os impactos ambientais ocasionados pelos resíduos de óleo de cozinha, é necessário um planejamento sustentável de um programa ou sistema de reciclagem do resíduo óleo de cozinha (COSTA et al., 2012). Portanto, o presente trabalho tem o objetivo de analisar a percepção ambiental dos moradores do município de Caçador/SC quanto à viabilidade da implantação de um sistema de reciclagem de resíduo de óleo de cozinha em biodiesel no município. 


\section{MATERIAIS E MÉTODOS}

A área de abrangência do estudo situa-se no município de Caçador/SC, como se pode verificar na figura 1, onde segundo informações do IBGE (2011), o município possui uma área de $981,901 \mathrm{~km}^{2}$, está a $920 \mathrm{~m}$ de altitude, clima subtropical úmido, e com uma densidade demográfica de $77,21 \mathrm{hab} / \mathrm{km}^{2}$, a qual 6.304 (8,91\%) residem em área rural e 64.431 (91.09\%) residem em área urbana.

A pesquisa é de caráter exploratório e não probabilística, onde contemplou 90 residências em diferentes bairros do município de Caçador. A coleta de dados foi realizada através de 9 escolas do município, com turmas de as turmas do 6ㅇ ao 9 ano, em um questionário semiestruturado pelos membros do projeto Óleo no Futuro - Foco na Logística. O questionário é composto de 8 perguntas, e foi aplicado no período de janeiro a dezembro de 2016, onde o material foi entregue aos alunos para levarem a suas residências para o preenchimento familiar, conforme descrito na tabela 1.

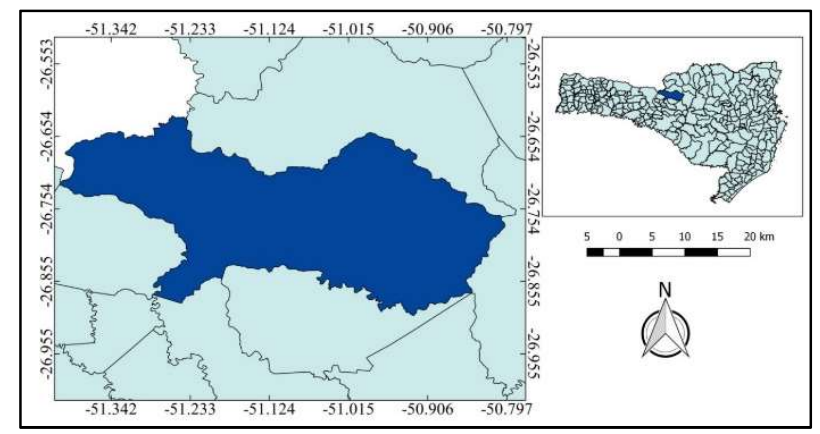

Figura 1. Mapa de localização da área de estudo.

Tabela 1: Escolas e localização da aplicação dos questionários.

\begin{tabular}{|c|c|c|c|}
\hline \multirow{2}{*}{ LOCAL DE ENTREGA DOS QUESTIONÁRIOS } & \multirow{2}{*}{ BAIRRO } & \multicolumn{2}{|c|}{ LOCALIZAÇÃO } \\
\hline & & X(lat.) & $\mathrm{Y}$ (Ion.) \\
\hline \multicolumn{4}{|c|}{ ESCOLAS DE EDUCAÇÃO BÁSICA MUNICIPAL } \\
\hline Alcides Tombini & Sorgatto & -26.78 & -51.02 \\
\hline Alto Bonito & Alto Bonito & -26.78 & -50.99 \\
\hline Henrique Julio Berger & Berger & -26.78 & -51.00 \\
\hline Professora Maria Luiza Martins Barbosa & Martello & -26.78 & -50.98 \\
\hline Doutor Ulysses Guimarães & Bom Sucesso II & -26.77 & -50.78 \\
\hline Pierina Santin Perret & Dos Municípios & -26.77 & -51.03 \\
\hline Morada do Sol & Martello & -26.79 & -50.99 \\
\hline \multicolumn{4}{|c|}{ ESCOLAS PARTICULARES } \\
\hline Colégio Aplicação & Centro & -26.77 & -51.01 \\
\hline
\end{tabular}

O estudo é um trabalho de pesquisa desenvolvido pelo curso de engenharia ambiental e sanitária da Universidade Alto Vale do Rio do Peixe (UNIARP), o qual, através do projeto 'Óleo no Futuro - Foco na Logística' busca implantar um sistema de transformação o resíduo do óleo de cozinha em biodiesel. As variáveis de análise do estudo foram relacionadas com a quantidade de óleo de cozinha que é gerado nas residências, qual a destinação do óleo de cozinha nas residências, e se houve a busca de alternativas corretas para o descarte de óleo de cozinha gerado nas residências.

Quanto ao conhecimento de transformação do óleo de cozinha em biodiesel, de alguma forma você se considera responsável pela poluição dos corpos hídricos, se os entrevistados aceitariam participar de um programa de reciclagem do óleo de cozinha, se acaso uma instituição realiza-se a reciclagem do óleo de cozinha os moradores estariam dispostos a armazenar e posteriormente levar o material coletado até a 
instituição, e se a implantação de um sistema de reciclagem do óleo de cozinha vai diminuir os impactos ocasionados no meio ambiente.

\section{RESULTADOS E DISCUSSÃO}

A figura 2 apresenta os resultados obtidos no questionário sobre a quantidade de resíduos de óleo de cozinha que é gerado nas residências. Quando solicitado sobre a quantidade de resíduos em suas residências, o estudo apresenta que 38,6\% (53 residências) geram de 1 a 2L; 32,8\% (42 residências) geram de 2 a 3L, 18,9\% (26 residências) geram de 4 e 5L; e 9,5\% (13 residências) geram acima de $5 \mathrm{~L}$ de resíduo de óleo de cozinha. Em um estudo de levantamento da geração de resíduos de óleo de cozinha em diferentes bares e restaures do município de Santa Maria/RS, apresenta uma geração média de 4874L por mês em 5 meses analisados (fevereiro a junho) (REQUE et al., 2010).

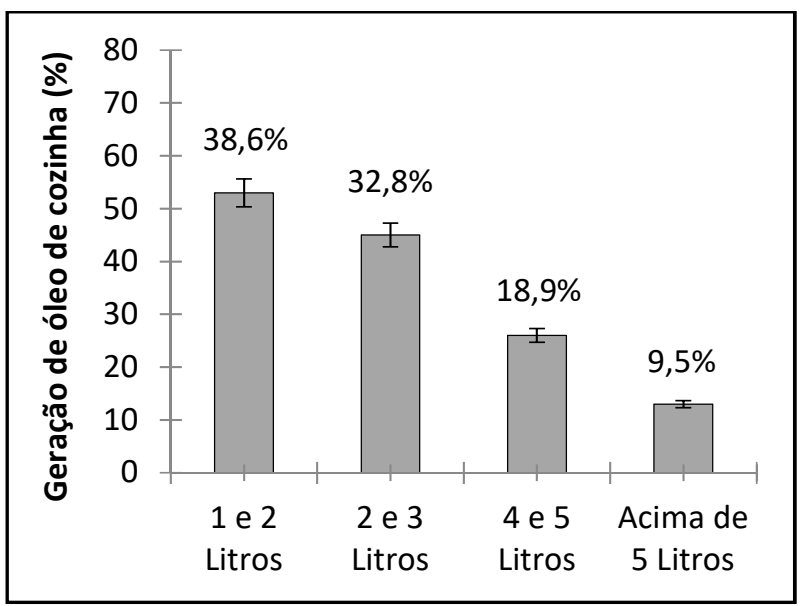

Figura 2: Percepção sobre a geração de resíduo óleo de cozinha nas residências.

Segundo a Associação Brasileira das Indústrias de Óleos Vegetais, o Brasil apresenta um consumo per capita de $10 \mathrm{~L}$ para o uso doméstico, obtendo uma geração de 500.000L de resíduo de óleo de cozinha; no entanto, desses, apenas 10\% (50.000L) são reciclados. Para Thode-Filho et al. (2013), o Brasil possui um potencial para a produção de energia limpa (Biodiesel) a partir do resíduo óleo de cozinha, podendo se consolidar entre os grandes países, devido à quantidade de resíduo que é gerado. A figura 3 apresenta os resultados obtidos no questionário sobre a destinação do resíduo óleo de cozinha nas residências.

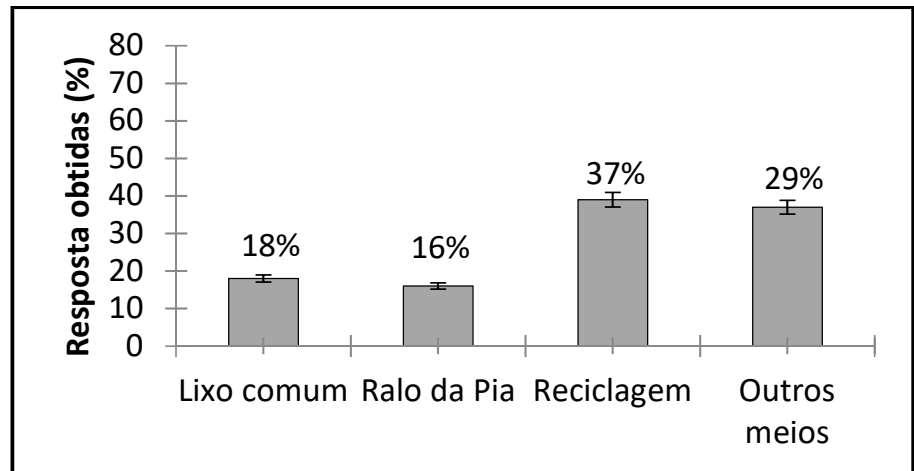

Figura 3: Percepção sobre a geração de resíduo óleo de cozinha nas residências. 
Quando questionados sobre a destinação do óleo em suas residências, $18 \%$ descartam no resíduo comum, $16 \%$ descartam no ralo da pia, $37 \%$ fazem reciclagem e $29 \%$ descartam por outros meio. Para Albercini et al. (2004), o descarte irregular de óleo de cozinha, pode ocasionar sérios danos à vida aquática, onde um litro de óleo é capaz de esgotar o oxigênio de $20.000 \mathrm{~L}$ de água devido ao bloqueio do ar e luz. Segundo Reque et al. (2010), 1L de óleo descartado no esgoto possui a capacidade de poluir cerca de 1.000.000 L de água. Uma alternativa para diminuir o descarte incorreto do resíduo de óleo de cozinha é a reciclagem (FREITAS et al., 2010). A figura 4 apresenta os resultados obtidos no questionário sobre a busca por alternativas ambientalmente correta para o descarte do óleo de cozinha.

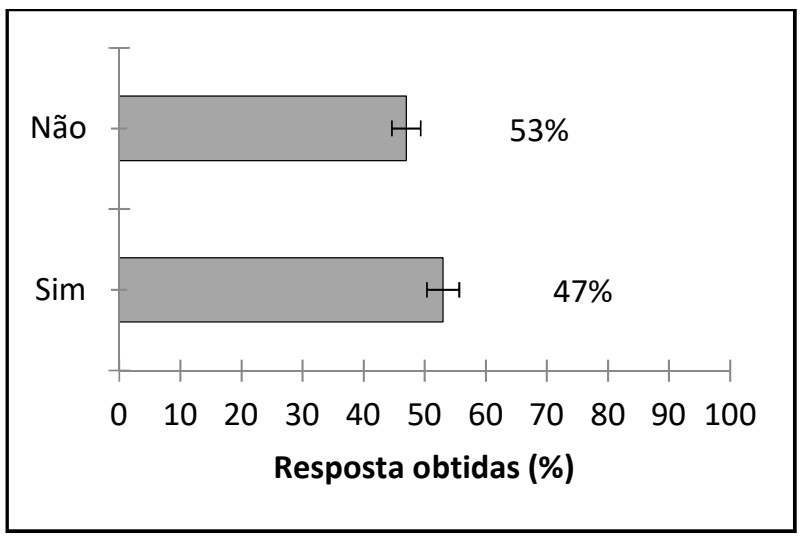

Figura 4: Percepção sobre a busca de alternativas viáveis para o resíduo de óleo de cozinha.

Quando questionado se os moradores buscam alternativas ambientalmente corretas para o descarte de resíduo de óleo de cozinha, 53\% responderam que buscam alternativas sustentáveis para o descarte do óleo de cozinha e $47 \%$ responderam que não buscar alternativas para o descarte. Segundo Pitta-Junior et al. (2009), os consumidores estão familiarizados com os efeitos adversos que o óleo de cozinha ocasiona no meio ambiente ou não possuem meios para o descarte adequado. Para Costa et al. (2015), a educação ambiental voltada para um pensamento holístico sobre a questão da reutilização do óleo de cozinha, na preservação do meio ambiente tornam-se imprescindíveis para a atividade de ajuda e colaboração sobre um tema. A figura 5 apresenta os resultados obtidos no questionário sobre a o conhecimento dos entrevistado sobre o processo de transformação do óleo de cozinha em biodiesel.

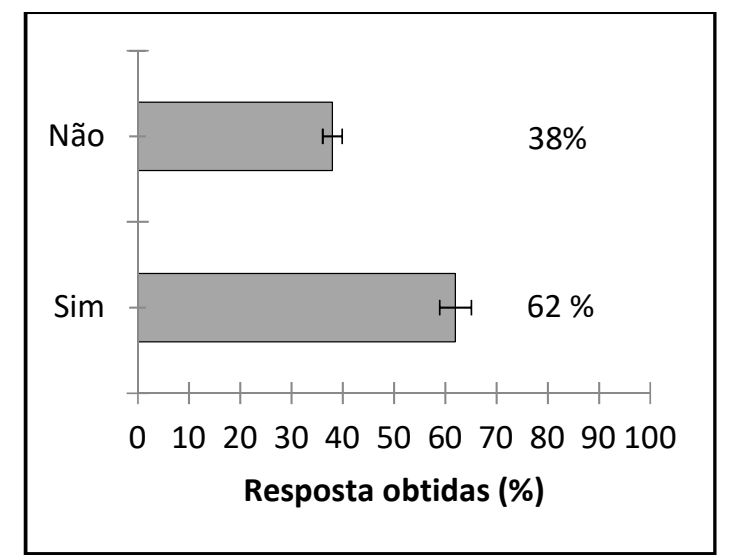

Figura 5: Percepção sobre o conhecimento da reciclagem do óleo de cozinha. 
Quando questionado sobre o conhecimento do processo de reciclagem do óleo de cozinha em biodiesel, $62 \%$ responderam que conhecem que o óleo de cozinha pode ser transformado em biodiesel e $38 \%$ responderam que não conhecem o processo de reciclagem. Para Reque et al. (2010), a falta de iniciativa pública para a coleta e tratamento do resíduo óleo de cozinha, influencia na divulgação sobre os meio de reciclagem. A figura 6 apresenta os resultados obtidos no questionário sobre o conhecimento da poluição dos corpos hídricos e se os mesmos se consideram responsáveis.

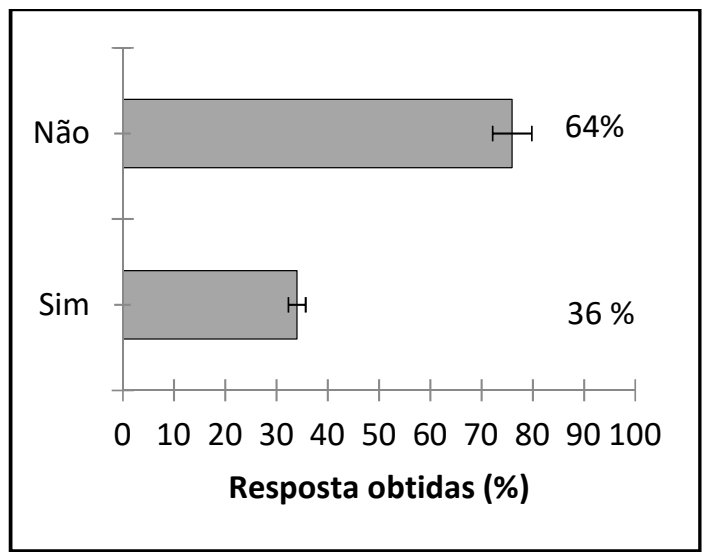

Figura 6: Percepção sobre a poluição hídrica.

Quando questionado sobre se os entrevistados se consideram responsáveis pela poluição dos corpos hídricos, 36\% responderam que sim que se consideram responsáveis pela poluição e $64 \%$ não se considera responsável. Para Martins et al. (2010) a aplicação da educação ambiental com ênfase em poluição dos recursos hídricos, como também apresentar característica corretas do descarte de óleo de cozinha, são caracterizados como métodos de preservar os recursos hídricos e indiretamente a qualidade de vida dos seres vivos.

Segundo Bósio (2014) em um estudo de percepção sobre o descarte de óleo de cozinha no município de Matelândia/PR, apresenta que a entrega de cartilhas sobre o processo de reciclagem e sobre os efeitos do óleo de cozinha ao meio ambiente é muito bem visto pela comunidade. Apresentando ser uma alternativa para o município de Caçador/SC, utilizar cartilhas para divulgar o processo de transformação do óleo de cozinha em biodiesel. A figura 7 apresenta os resultados obtidos no questionário sobre se os moradores aceitariam participar de um projeto de reutilização de óleo de cozinha com o objetivo de transformar o resíduo em biodiesel, sabão e outros com o intuito de preservar os recursos naturais.

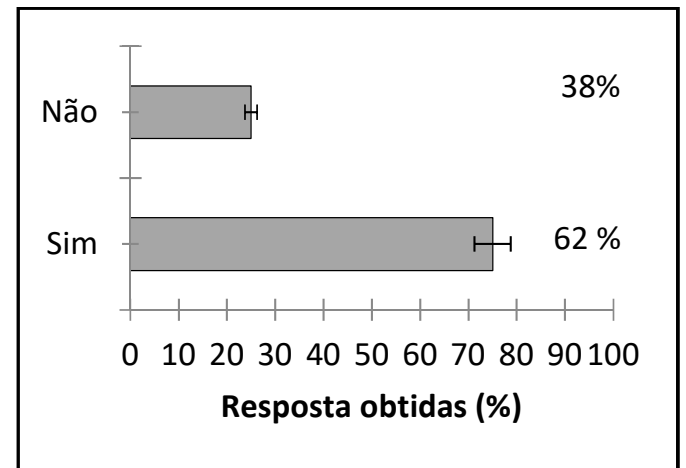

Figura 7: Percepção sobre a participação em um sistema de reciclagem do óleo de cozinha. 
Quando questionado sobre se os moradores aceitaram participar de um programa de reciclagem de óleo de cozinha, $75 \%$ das pessoas aceitaram participar o projeto de reutilização de óleo de cozinha e $25 \%$ responderam que não tem interesse em participar de um programa desse gênero. Segundo Monte et al. (2015) para que um processo de reuso ou reciclagem obtenha sucesso é necessário o comprometimento do município, das entidade ambientais, das escolas e de todos os envolvidos com a atual situação.

Buscando uma comunidade consciente, mas principalmente as crianças e adolescentes, pois são os responsáveis pelo futuro de uma população. A figura 8 apresenta os resultados obtidos no questionário sobre se os moradores estariam dispostos a armazenar e posteriormente levar os resíduos óleo de cozinha para uma universidade do município que almeje a reciclagem desse resíduo.

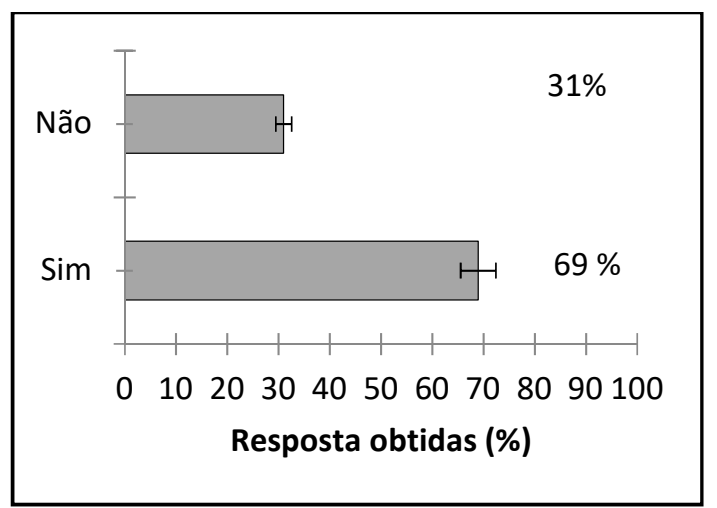

Figura 8: Percepção sobre se os moradores realizassem a separação e armazenamento do resíduo de óleo de cozinha.

Quando questionado se os moradores realizassem o armazenamento e posteriormente destinação para uma universidade que realizasse a reciclagem do óleo de cozinha, $69 \%$ responderam que toparia participar do sistema de reciclagem e $31 \%$ responderam que não topariam participar do sistema de reciclagem do resíduo. Para Reque et al. (2010), a utilização de garrafas Pet como meio de armazenar óleo de fritura usado para posteriormente obter uma possível destinação correta é vista como um inconveniente, onde muitos preferem destinar esse material de forma inadequada como pias e vasos sanitários.

Quando questionados sobre a viabilidade da implantação de um sistema de reciclagem do óleo de resíduo, $94 \%$ que a pratica deste sistema diminuirá a poluição do meio ambiente e $6 \%$ responderam que esse sistema não vai auxiliar na diminuição da poluição. Segundo Costa, Lopes e Lopes (2015) para melhor a conservação e a qualidade de vida na terra é necessário buscar alternativas viáveis para os problemas ambientais. Conforme Mota et al., (2015) a criação de programas de coleta e reciclagem de óleo de cozinha é uma estratégia que auxilia no combate as degradações ambientais, a disseminação de doenças, utilização eficiente da matéria prima e promove a integração social. Para Pitta-Junior (2009) programas de reciclagem podem amenizar a poluição, economizar dinheiro dos contribuintes, evitar problemas na rede de esgoto e gerar combustível. O processo de reciclagem do óleo de cozinha pode gerar renda para as pessoas envolvidas (GODOY et al., 2010).

Essa falta de interesse dos morados entrevistados, está associado com a falta de conscientização ambiental, mostrando que mesmo sabendo dos efeitos adversos ao meio ambiente os moradores do estudo precisam de educação ambiental ou incentivo no processo de armazenamento. A figura 9 apresenta os 
resultados obtidos no questionário sobre se moradores considerariam a implantação de sistema de reciclagem do óleo de cozinha pela universidade como um alternativa para diminuição da poluição do meio ambiente.

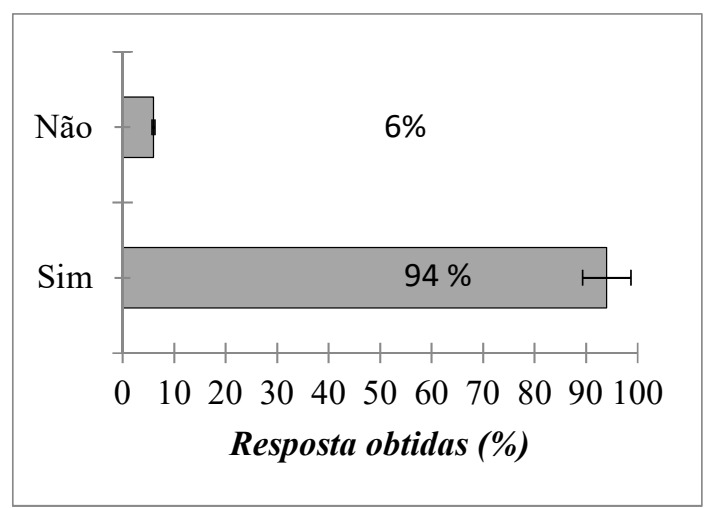

Figura 9: Percepção sobre se um programa de reciclagem do resíduo de óleo de cozinha realizasse a diminuição da poluição dos corpos hídricos.

Segundo Deboni et al. (2015), a aplicação do Plano de Gerenciamento de Resíduos Sólidos (PGRS) é um método de disponibilização de informações sobre as questões ambientais, pois em seu estudo de percepção ambiental no município de Lages/SC. Pode-se concluir que muitos moradores adotam boas pratica de minimização de impacto ambiental. Porém, é necessário o investimento em educação ambiental através de ações de conscientização, para uma atuação em todos os aspectos ambientais do município.

Atualmente o município de Caçador não possui o PGRS desenvolvido e aplicado com a comunidade do município de Caçador, no entanto, visto que o mesmo auxiliaria nas diretrizes do manejo e destinação dos resíduos de óleo de cozinha. Segundo Almeida (2012) e Campos et al. (2015) o município de Caçador, através da Fundação Municipal do Meio Ambiente - FUNDEMA, está desenvolvendo estudos para melhor o processo de gestão (diretrizes) dos resíduos sólidos urbanos e rurais. Porém, os autores ressaltam a importância da educação ambiental para solucionar a problemática dos resíduos no município. Essa questão pode ser constatada através deste trabalho, pois a alguns entrevistados descartam o resíduo óleo de cozinha de forma inadequada.

Aliado ao processo de educação ambienta, o processo de reciclagem do óleo de cozinha é um processo que diminui a quantidade de resíduos descartados de forma inadequada do resíduo. Conforme Ghesti et al. (2011) a utilização de projetos que reciclem o resíduo de óleo de cozinha em biodiesel é um método de incentivo para a educação ambiental da população envolvida. Para Gui et al. (2008), a transformação do óleo de cozinha em biodiesel é uma alternativa viável para a reciclagem do óleo de cozinha, visto que esse processo é suficiente para atender a demanda do Biodiesel. Segundo Korakaki et al. (2014), o processo de transformação do resíduo de óleo de cozinha em biodiesel é viável para um escala produtiva, devido ao preço do produto.

\section{CONCLUSÕES}

Com o estudo, pode-se concluir que é viável a implantação de um sistema de transformação do resíduo de óleo de cozinha em biodiesel, pois a maioria dos entrevistados concorda em participar do 
programa de reciclagem, quanto também conhecem a importância desse programa para a preservação dos recursos hídricos do município. Muitos moradores concordaram em participar do sistema de reciclagem, porém, muitos dos que se habilitaram a participar do sistema não estão dispostos a armazenar o material em suas residências para posteriormente destinar à instituição, para que haja eficiência do processo de reciclagem, para, por conseguinte, ser desenvolvido um sistema de coleta nas residências, o qual pode ser desenvolvido pela ampliação do sistema convencional de coleta seletiva do município de Caçador.

O estudo também apresenta à necessitada do incentivo de instituições públicas e privados através de práticas de educação ambiental voltada para o processo de gestão dos resíduos de óleo de cozinha da comunidade, para diminuir os impactos ambienta ocasionados pelos resíduos, como também para conscientizar a população. Esta questão pode ser saneada com a utilização de meios informativos (jornais, rádios, panfletos e outros), palestra em escolas públicas e privadas, e outros.

\section{REFERÊNCIAS}

ALBERICI, R. M.; PONTES, F. F. F.. Reciclagem de óleo comestível usado através da fabricação de sabão. Revista Engenharia Ambiental, Espírito Santo do Pinhal, v.1, n.1, p.73-76, 2004.

ALMEIDA, R.G.. Estudo da geração de resíduos sólidos domiciliares urbanos do município de Caçador/SC a partir da caracterização física e composição gravimétrica. Revista Ignis, v.1, n.1, p.51-70, 2012.

BÓSıO, P.. Caracterização do descarte do óleo de cozinha utilizado no Município de Matelândia e seus impactos no meio ambiente. Monografia (Especialização em Gestão Ambiental em Municípios) - Universidade Tecnológica Federal do Paraná, Rebouças, 2014.

BRAGA, B.; HESPANHOL, I.; CONEJO, J. G. L.; MIERZWA, J. C.; BARROS, M. T. L.; SPENCER, M.; PORTO, M.; NUCCI, N.; JULIANO, N.; EIGER, S.. Introdução à engenharia ambiental: o desafio do desenvolvimento sustentável. 2 ed. São Paulo: Pearson Prentice Hall, 2005.

CAMPOS, R. F. F.; BORGA, T.. Caracterização gravimétrica do material reciclável destinado à Coocima pelo programa de coleta seletiva do município de Caçador/SC. Revista Eletrônica em Gestão, Educação e Tecnologia Ambiental, Santa Maria, v.19, n.3, p.325-338, 2015.

CASTELLANELLI, C.; MELLO, C. I.; RUPPENTHAL, J. E.; HOFFMANN, R.. Óleos comestíveis: o rótulo das embalagens como ferramenta informativa. In: ENCONTRO DE SUSTENTABILIDADE EM PROJETO DO VALE DO ITAJAÍ. Anais. Florianópolis: UFSC, 2007.

CHHETRI, A. B.; WATTS, K. C.; ISLAM, M. R.. Waste cooking oil as an alternate feedstock for biodiesel production. Energies, v.1, n.1, p.3-18, 2008.

COSTA, D. A.; LOPES, G. R.; LOPES, J. R.. Reutilização do óleo de fritura como uma alternativa de amenizar a poluição do solo. Revista Monografias Ambientais, v.14, p.243-253, 2015.
DEBONI, T. L.; MOMBACH, G. N. N.; LOPES, M. N.; SIMIONI, F. J.. Percepção e Consciência Ambiental: Um estudo exploratório em Lages/SC. Revista Geoambiente On-line. n.24, v.2, 2015.

FREITAS, C. F.; BARATA, R. A. R.; NETO, L. S. M.. Utilização do óleo de cozinha usado como fonte alternativa na produção de energia renovável, buscando reduzir os impactos ambientais. In: ENCONTRO NACIONAL DE ENGENHARIA DA PRODUÇÃO, 30. Anais. Maceió: ABEPRO, 2010.

GHESTI, G. F.; RODRIGUES, J. P.; SOUZA, J. S. A.; MACEDO, J. L.; GAIO, L. M.; SILVA, J. S.. A educação ambiental na Engenharia e a reciclagem de óleo residual coletado: projeto de extensão Biogama. Revista ParticipAção, v.16, n.1, p.2937, 2011.

GODOY, P. O.; OLISKOVICZ, K.; BERNARDINO, V. M.; CHAVES, W. R.; PIVA. D. C.; RIGO, A. S. N.. Consciência limpa: Reciclando o óleo de cozinha. Anuário da Produção de Iniciação Científica Discente, v.13, n.17, p.205-2017, 2010.

GOMES, A. P.; CHAVES, T. F.; BARBOSA, J. N.; BARBOSA, E. A.. $A$ questão de descarte de óleo e gorduras vegetais hidrogenadas residuais em indústrias alimentícias. In: ENCONTRO NACIONAL DE ENGENHARIA DE PRODUÇÃO, 33. Anais. Maceió: ABEPRO, 2013.

GONÇALVES, M. F. S.; CHAVES, G. L. D.. Perspectiva do Óleo Residual de Cozinha (ORC) no Brasil e suas dimensões na Logística Reversa. Espacios, v.35, n.8, p.16, 2014.

GUI, M. M.; LEE, K. T.; BHATIA, S.. Feasibility of edible oil vs. non-edible oil vs. waste edible oil as biodiesel feedstock. Energy, v.33, n.1, p.1646-1653, 2008.

HANISAH, K.; KUMAR, S.; TAJUL, A. Y.. The management of waste cooking oil: a preliminary survey. Health and the Environment Journal, v.1, n.1, p.76.81, 2013.

IBGE. Instituto Brasileiro de Geografia e Estatística. Contas nacionais: Sistemas de Contas Nacionais. Rio de Janeiro: IBGE, 2011. 
KORAKAKI, M.; GEORGAKELLOS, D.. Feasibility evaluation of a biodiesel plant fed by recucled edible oils comparing two alternative production technologies. Global NEST Journal, v.16, n.1, p.2-10, 2014.

MARTINS, C. T.; CONTI, Z. T.; LISBOA, V. G.; MARTINS, C. T.. Uma alternativa consciente de reaproveitamento do óleo de cozinha: a fabricação de sabão caseiro. In: Encontro Latino Americano de Pós-Graduação, 10. Anais. São José dos Campos: Universidade do Vale do Paraíba, 2010.

MONTE, E. F.; FAGUNDES, T. C.; XIMENES, A. F.; MOURA, F. S.; COSTA, A. R. S.. Impacto ambiental causado pelo descarte de óleo: estudo de caso da percepção dos moradores de Maranguape I, Paulista - PE. Revista GEAMA, Recife, v.2, n.1, p.41-55, 2015

PITTA-JUNIOR, O. S.; NOGUEIRA-NETO, M. S.; SACOMANO, J. B.; LIMA, J. L. A.. Reciclagem do óleo de cozinha usado: uma contribuição para aumentar a produtividade do processo. In: INTERNATIONAL WORKSHOP | ADVANCES IN CLEANER PRODUCTION, 2. Anais. São Paulo: USP, 2019.

ROQUE, P. T.; KUNKEL, N.. Quantificação do óleo residual de fritura gerado no município de Santa Catarina/RS.

Disciplinarum Scientia. Santa Maria, v.11, n.1, p.50-63, 2010.

THODE-FILHO, S.; SILA, W. F. M.; SILVA, E. R.; SANTOS, A. S.; ALMEIDA, T. M.. Incentivo à produção de biodiesel a partir do óleo vegetal residual. Revista Educação, Gestão e Sociedade, Jandira, n.10, v.3, 2010.

TREVISOL, J. V.. A educação em uma sociedade de risco: tarefas e desafios na construção da sustentabilidade. Joaçaba: UNOESC, 2003. 